\title{
Direct and Indirect Effects of Pseudoephedrine on the Intrinsic Conduction System of the Embryonic Chicken Heart
}

\author{
Samely Gonzalez, Fatima Afzal and Dr. Jacqueline S. McLaughlin \\ Department of Biology, Penn State Lehigh Valley, Center Valley, PA \\ Students: gnzlz_smly2@yahoo.com,fia5083@psu.edu \\ Mentor: jxm57@psu.edu
}

\begin{abstract}
Pseudoephedrine (PSE) is an over the counter (OTC) medication used to temporarily relieve nasal congestion, hay fever or other upper respiratory allergies by shrinking blood vessels in the nasal passages. Aside from its vasoconstriction properties it is also known to elevate heart rate, and blood pressure, thus being a sympathomimetic drug. There are two hypotheses on how this drug increases heart rate (HR): (1) a direct mechanism wherein PSE works by binding to adrenergic receptors in the heart's intrinsic conduction system; and, (2) an indirect mechanism wherein PSE causes the release of norepinephrine from sympathetic nerves to activate adrenergic receptors. This research utilized the chick embryonic heart as a model system to examine the chronotropic effects and mechanisms of PSE on the developing vertebrate heart. Research suggests that this drug has both direct and indirect effects, and induces dangerous heart arrhythmias such as atrial flutter, in high doses.
\end{abstract}

\section{KEYWORDS}

Pseudophedrine, Sympathomimetic Drugs, Pseudophedrine and Pregnancy, Pseudophedrine and Norepinephrine, Pseudophedrine Related Arrhythmias, Over-the-counter Drugs; Chick Heart Development

\section{INTRODUCTION}

Psuedoephederine (PSE) is the active ingredient in many Food and Drug Administration (FDA)-approved nasal decongestant products, including Sudafed ${ }^{\circ}$. Despite its wide distribution in local pharmacies and its common use, Sudafed ${ }^{\circ}$ has become a topic of interest in drug research due to its numerous side effects on the cardiovascular system such as increased heart rate. The autonomic regulation of $\mathrm{HR}$ relies on two branches of the autonomic nervous system, sympathetic and parasympathetic, which have an impact on the electrical impulses and the timing that are generated from the SA node. ${ }^{4}$ The sympathetic division speeds up pacemaker's depolarization via the exocytosis of norepinephrine (NE), while the parasympathetic division slows it down by releasing acetylcholine. Even though this drug has been proven to affect the cardiovascular system, it is unclear whether it works on the heart via a direct or indirect mechanism. The two hypotheses regarding these mechanisms are the following: (1) A direct mechanism wherein PSE works by binding to adrenergic receptors in the heart's intrinsic conduction system; and, (2) an indirect mechanism of action is via stimulating the release of NE from presynaptic nerve endings which then freely activate $\alpha$ - and $\beta$-adrenergic receptors located within the SA node and the muscle lining walls of blood vessels. The adrenergic receptors are a class of $\mathrm{G}$ protein-coupled receptors that bind agonists such as catecholamines to generally stimulate the sympathetic nervous system. Activation of the beta receptor leads to increases in contractile force and heart rate. Activation of alpha receptors by either sympathetic nervous system transmission or drugs will result in vasoconstriction and an increase in peripheral resistance and systemic arterial blood pressure. ${ }^{5}$ It is noteworthy to mention that the parasympathetic nervous system works through a different set of receptors not $\alpha$ - and 
$\beta$-adrenergic receptors.

Studies on anesthetized adult rats showed that PSE causes dose-dependent increases in arterial blood pressure and heart rate (HR). The increase in HR disappeared after the destruction of the sympathetic nerve terminals, suggesting that PSE's mechanism of action is indirect and innervation is needed to affect the HR. ${ }^{6}$ This rules out a direct effect because after the termination of the sympathetic nerves, the receptors on the heart were still present and could technically still be bound by PSE to increase the HR; however, the heart rate no longer increased even though the receptors were exposed to the drug, suggesting the inability of PSE to directly bind to the receptors. Based on these findings, it was hypothesized that PSE will exhibit dose-dependent chronotropic effects on the in vitro 6-day intact chick embryo, but not on an in vitro denervated 6-day chick heart. It was reasoned that the 6 -day isolated heart without innervation will not have the capability to respond to this drug due to the disruption of sympathetic nerve input.

Avian organisms are commonly used as model systems for the study of the cardiovascular system in humans as both systems share a four-chambered heart. During bird and human heart development, endothelial tubes fuse to form four distinct regions: ventricle, atrium, conotruncus (aka bulbus cordis), and the sinus venosus. The latter functions as the embryonic pacemaker. Once the four-chambered heart is developed, between days 6-7, the sinus venosus becomes the mature pacemaker or sinoatrial node (SA node). ${ }^{1,2,3}$ The SA node is a cluster of auto-rhythmic cells located in the wall of the right atrium that sets the rate and timing at which cardiac muscle cells contract. However, the adrenergic receptors located at the SA node are influenced by neurotransmitters or sympathomimetic drugs, therefore changing the normal auto-rhythm of the SA node cells. Overall, this research on the fetal heart system provides an understanding of sympathomimetic drugs and the adrenergic receptors at which these drugs interact. Understanding and awareness of such drugs is critical because they are widely used by the general public as a nasal decongestant and by medical professionals to treat cardiac arrest, and low blood pressure, among other things.

\section{METHODS AND MATERIALS}

\section{A. Serial Dilution}

A 10-fold serial dilution of PSE was prepared using a PSE stock solution of $3 \mathrm{mg} / \mathrm{mL}$ in CMRL $10661 \mathrm{X}$ Media (Mediatech Inc., Manassas, VA) to yield the following concentrations: $3 \times 10^{-1} \mathrm{mg} /$ $\mathrm{mL}, 3 \times 10^{-2} \mathrm{mg} / \mathrm{mL}, 3 \times 10^{-3} \mathrm{mg} / \mathrm{mL}, 3 \times 10^{-4} \mathrm{mg} / \mathrm{mL}$, and $3 \times 10^{-5} \mathrm{mg} / \mathrm{mL}$.

\section{B. Windowing the Egg - $\mathrm{Cruz}^{7}$}

A 6-day fertilized broiler egg was removed from a $41^{\circ} \mathrm{C}$ egg incubator into a $110 \mathrm{~mm}$ glass dish lined with cotton, maintaining its horizontal position. While keeping the egg warm under a goose neck lamp with $100 \mathrm{~W}$ bulb, Scotch ${ }^{\oplus} \mathrm{Magic}^{\mathrm{m}}$ tape was placed along the long axis of the egg. A dissecting needle was used to puncture a hole in the blunt end of the egg. Then, a $20 \mathrm{G}$ needle with syringe was inserted into the hole to remove approximately $1-2 \mathrm{~mL}$ of albumen. Next, an oval opening was cut with micro-dissecting scissors, exposing the embryo and its extra-embryonic membranes.

\section{Explanting the Embryo - $\mathrm{Cruz}^{7}$}

Using an embryo spoon and micro-dissecting scissors, the extra-embryonic membranes were cut to explant the embryo into a $65 \mathrm{~mm}$ Syracuse glass dish containing warmed CMRL media on the stage of a dissecting microscope. The chick explant was oriented so the right side was facing upward to allow access to the beating heart. 


\section{Heart Isolation - McLaughlin and McCain ${ }^{8}$}

The beating heart was removed with surgical scissors and fine forceps by cutting it above the conotruncus and below the SA node or atrium. The excised heart was transferred into a Bioptechs EDU Series Culture Dish Control System (Butler, PA), attached to a dissecting microscope, to maintain normal avian body temperature at $41^{\circ} \mathrm{C}$. Its control $\mathrm{HR}$ (beats per minute) was then visually assessed and recorded without drug. HR was recorded in three intervals of 15 seconds each, using a stopwatch, and then averaged.

\section{E. Application of Pseudoephedrine}

The isolated hearts were suspended in five PSE concentrations starting with lowest $\left(3 \times 10^{-5} \mathrm{mg} /\right.$ $\mathrm{mL})$ to highest $\left(3 \times 10^{-1} \mathrm{mg} / \mathrm{mL}\right)$. Previous concentrations of drug were removed with a transfer pipette properly labeled as drug with labeling tape and indelible ink pen. HRs and arrhythmias were recorded for each concentration following an approximate 30 second period of equilibration. For whole embryos, the in vitro HR was recorded without the drug (control) and again in each PSE concentration from lowest to highest (Figures 1 and 2). Any heart arrhythmias that were observed were also recorded.

\section{F. Statistical Analysis}

Polynomial regression analysis was chosen to represent the non-linear trend in the data points between the varying concentrations of PSE and HR. Furthermore, a second order polynomial trend line is selected to set the data on the graph to best address the number of fluctuations. The second-order quadratic equation is represented in quadratic form, $y=a x^{2}+b x+c$. In Figure 4, error bars represent one standard deviation above and below the mean $(\mathrm{SD} \pm 1)$ for both the isolated heart and whole embryo trials. To clarify, the mean of trials 1-3 was calculated for both the isolated hearts and whole embryos separately, and then the custom STDEV.S function in MS Excel was applied to calculate the error bars (note: this function calculates the standard deviation of a sample, rather than of a larger population). The more the raw data values lie above and below the mean, the wider the error bars and less confident one can be in a particular value. If the upper error bar for one drug concentration overlaps the range of values within the error bar of another drug concentration, there is a much lower likelihood that these two values differ significantly. ${ }^{9}$
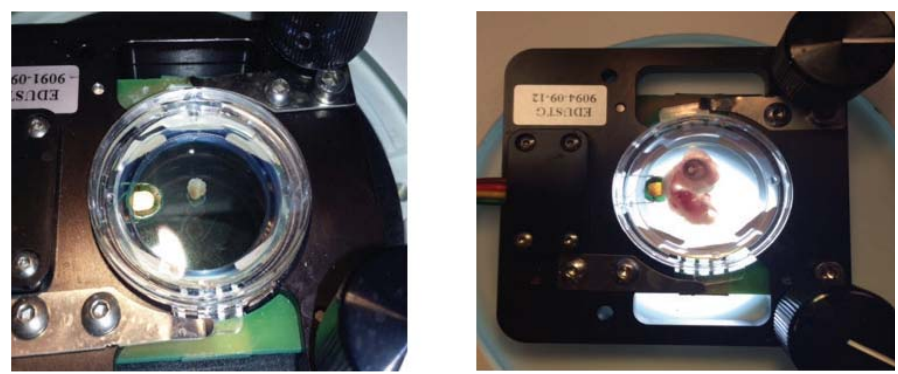

Figure 1. Delta T-EDU Bioptechs apparatus illustrating a 6-day isolated chick heart. (left)

Figure 2. Delta T-EDU Bioptechs apparatus illustrating a 6-day whole chick embryo. (right) 


\section{RESULTS}

Polynomial regression analysis was used to interpret the relationship between HRs and increasing PSE concentrations. Three experimental trials were carried out, each consisting of an isolated 6-day chick heart and a whole 6-day chick embryo. Additionally, polynomial trend lines were used to best present the overall trends as data fluctuated between concentrations. Figure $\mathbf{3}(\mathbf{a}, \mathbf{b}, \mathbf{c})$ presents polynomial regressions that plot HR vs. PSE concentrations for all three trials. Control data is also plotted on the graphs, which reflect HR of isolated heart and whole embryo without drug (CMRL media only). Additionally, Tables $\mathbf{1}$ and $\mathbf{2}$ display the average HR values for the isolated hearts and whole embryos along with observations of arrhythmias per concentrations. The isolated heart 1 and whole embryo 1 data shown in the tables below make up the first trial, isolated heart 2 and whole embryo 2 are compared as the second trial, and isolated heart 3 and whole embryo 3 were compared as the third trial. Overall, the following consistent pattern is seen throughout all three trials; an increase in HR towards the mid-concentration of $3 \times 10^{-1} \mathrm{mg} / \mathrm{mL}$ followed by a gradual decrease in HR towards the highest concentration of $3 \times 10^{-1} \mathrm{mg} / \mathrm{mL}$. Tachycardia was most prevalent at lower concentrations followed by atrial flutter and bradycardia towards the highest concentrations, in which some cases lead to cardiac arrest. For example, the isolated heart of trial 1 showed a control HR of 125 beats per minute (bpm) which then increased to $188 \mathrm{bpm}$ at the concentration of $3 \times 10^{-3} \mathrm{mg} / \mathrm{mL}$, illustrating tachycardia. This accelerated HR then fell to $73 \mathrm{bpm}$ at the highest concentration at $3 \times 10^{-1} \mathrm{mg} / \mathrm{mL}$, therefore bradycardia was observed along with atrial flutter.

Figure 4 illustrates a graphical presentation of the average HRs of 6-day isolated hearts and whole embryos exposed to varying concentrations of PSE (the three trials presented above as well as the control data without drug). The polynomial regression line models the same overall trend between the average HRs and PSE concentrations, revealing a polynomial increase in HR up until $3 \times 10^{-3}$ $\mathrm{mg} / \mathrm{mL}$, followed by a gradual decrease until the highest concentration, $3 \times 10^{-1} \mathrm{mg} / \mathrm{mL}$. Standard error bars were determined to evaluate the uncertainty around the estimate of the mean measurement. Standard error is used as a measurement of precision of the sample mean, and depends largely on both standard deviation and sample size. The error bars that are displayed in Figure 4 represent one standard deviation above and below the expected HR values plotted for each drug concentration. The average HR data indicates a $68 \%$ confidence interval of the data set with respect to the mean. Clearly, the distance between the two means for each concentration overlaps. This suggests statistical insignificance.

It is noteworthy to mention that aside from recording HRs, meticulous observations were made on the sinus rhythm of the chick hearts exposed to various PSE concentrations. The isolated chick hearts and whole chick embryos exposed to the drug experienced many arrhythmias. After the control media was removed and the lowest concentration was added, episodes of tachycardia were the most prevalent arrhythmias observed. However, at the highest concentrations of PSE, $3 \times 10^{-1}$ $\mathrm{mg} / \mathrm{mL}$, bouts of atrial flutter, bradycardia, and cardiac arrest were the most predominant effects. In a developing vertebrate heart tachycardia can be categorized as a sinus rhythm over $160 \mathrm{bpm}$, while bradycardia describes a sinus rhythm in which the heart rate is around $90 \mathrm{bpm}$. As for atrial flutter the heart rate in the atrium is usually very fast, often in the range of 350-500 beats per minute. Fortunately, the AV node is usually incapable of transferring impulses at such a fast rate, so only every other or every third impulse is conducted to the ventricles, this result in a heart rate in the ventricles that is much slower than the atrium, but still usually faster than normal. 


\begin{tabular}{|c|c|c|c|c|c|c|}
\hline Concentrations & $\begin{array}{r}\text { Isolated } \\
\text { Heart } 1 \\
\end{array}$ & Observations & $\begin{array}{l}\text { Isolated } \\
\text { Heart } 2 \\
\end{array}$ & Observations & $\begin{array}{l}\text { Isolated } \\
\text { Heart } 3 \\
\end{array}$ & Observations \\
\hline \multirow{2}{*}{ No drug } & Avg. & \multirow{2}{*}{$\begin{array}{l}\text { Normal sinus } \\
\text { rhythm }\end{array}$} & Avg. & \multirow{2}{*}{$\begin{array}{c}\text { Tear in atria; } \\
\text { normal sinus } \\
\text { rhythm }\end{array}$} & Avg. & \multirow{2}{*}{$\begin{array}{l}\text { Normal sinus } \\
\text { rhythm }\end{array}$} \\
\hline & 125 & & 156 & & 105 & \\
\hline $3 \times 10^{-5} \mathrm{mg} / \mathrm{mL}$ & 100 & $\begin{array}{l}\text { Normal sinus } \\
\text { rhythm }\end{array}$ & 140 & Atrial flutter & 115 & $\begin{array}{l}\text { Normal sinus } \\
\text { rhythm }\end{array}$ \\
\hline $3 \times 10^{-4} \mathrm{mg} / \mathrm{mL}$ & 188 & Tachycardia & 137 & Atrial flutter & 177 & Tachycardia \\
\hline $3 \times 10^{-3} \mathrm{mg} / \mathrm{mL}$ & 188 & Tachycardia & 165 & Atrial flutter & 188 & Tachycardia \\
\hline $3 \times 10^{-2} \mathrm{mg} / \mathrm{mL}$ & 171 & Tachycardia & $\mathrm{CA}$ & $\begin{array}{c}\text { Cardiac arrest } \\
\text { (CA) }\end{array}$ & 134 & $\begin{array}{c}\text { Periods of } \\
\text { tachycardia and } \\
\text { bradycardia }\end{array}$ \\
\hline $3 \times 10^{-1} \mathrm{mg} / \mathrm{mL}$ & 73 & $\begin{array}{c}\text { Atrial flutter; } \\
\text { bradycardia }\end{array}$ & CA & CA & 97 & $\begin{array}{l}\text { Bradycardia; } \\
\text { periods of atrial } \\
\text { flutter }\end{array}$ \\
\hline
\end{tabular}

Table 1. Average of heart rates (HRs) in beats per minute (bpm) of three isolated hearts with respects to increasing pseudoephedrine (PSE) concentrations.

\begin{tabular}{|c|c|c|c|c|c|c|}
\hline Concentrations & $\begin{array}{c}\text { Whole } \\
\text { Embryo } 1\end{array}$ & Observations & $\begin{array}{c}\text { Whole } \\
\text { Embryo } 2\end{array}$ & Observations & $\begin{array}{c}\text { Whole } \\
\text { Embryo } 3\end{array}$ & Observations \\
\hline \multirow{2}{*}{ No drug } & Avg. & \multirow{2}{*}{$\begin{array}{l}\text { Normal sinus } \\
\text { rhythm }\end{array}$} & Avg. & \multirow{2}{*}{$\begin{array}{l}\text { Normal sinus } \\
\text { rhythm }\end{array}$} & Avg. & \multirow{2}{*}{$\begin{array}{l}\text { Normal sinus } \\
\text { rhythm }\end{array}$} \\
\hline & 128 & & 121 & & 120 & \\
\hline $3 \times 10^{-5} \mathrm{mg} / \mathrm{mL}$ & 91 & Bradycardia & 143 & $\begin{array}{l}\text { Normal sinus } \\
\text { rhythm }\end{array}$ & 156 & $\begin{array}{l}\text { Normal sinus } \\
\text { rhythm }\end{array}$ \\
\hline $3 \times 10^{-4} \mathrm{mg} / \mathrm{mL}$ & 124 & $\begin{array}{l}\text { Normal sinus } \\
\text { rhythm }\end{array}$ & 153 & $\begin{array}{l}\text { Normal sinus } \\
\text { rhythm }\end{array}$ & 170 & Tachycardia \\
\hline $3 \times 10^{-3} \mathrm{mg} / \mathrm{mL}$ & 136 & $\begin{array}{l}\text { Normal sinus } \\
\text { rhythm }\end{array}$ & & $\begin{array}{l}\text { No data } \\
\text { (lab error) }\end{array}$ & 183 & Tachycardia \\
\hline $3 \times 10^{-2} \mathrm{mg} / \mathrm{mL}$ & 91 & Bradycardia & 170 & Tachycardia & $\mathrm{CA}$ & $\begin{array}{l}\text { Bradycardia; } \\
\text { atrial flutter }\end{array}$ \\
\hline $3 \times 10^{-1} \mathrm{mg} / \mathrm{mL}$ & 75 & $\begin{array}{l}\text { Bradycardia; } \\
\text { atrial flutter }\end{array}$ & 36 & $\begin{array}{l}\text { Bradycardia; } \\
\text { atrial flutter }\end{array}$ & $\mathrm{CA}$ & Cardiac arrest \\
\hline
\end{tabular}

Table 2. Average of heart rates (HRs) in beats per minute (bpm) of three whole embryos with respect to increasing pseudoephedrine (PSE) concentrations. 


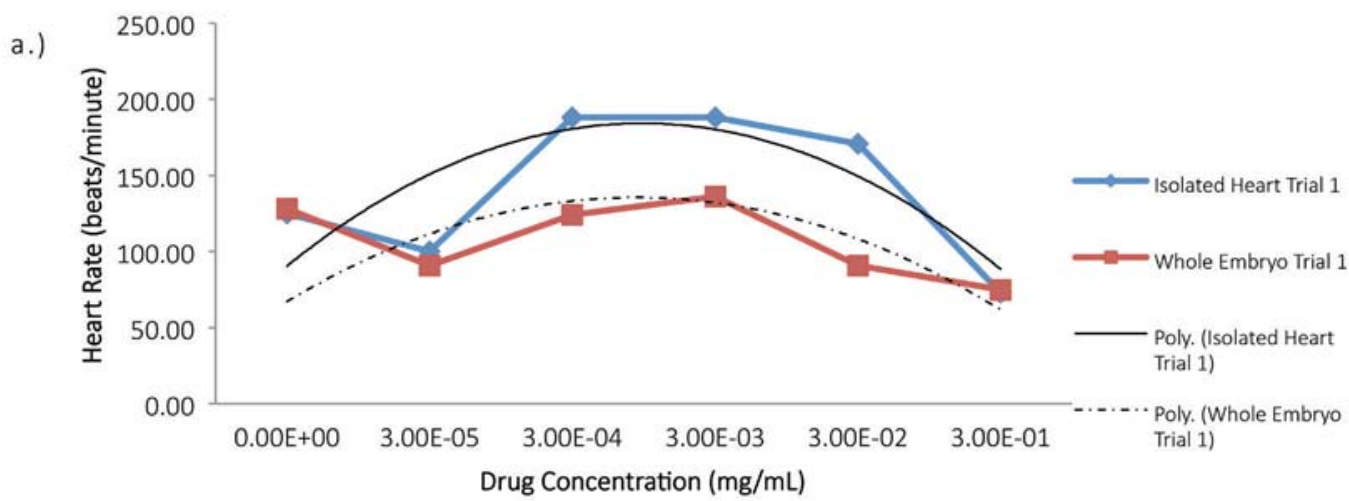

b.
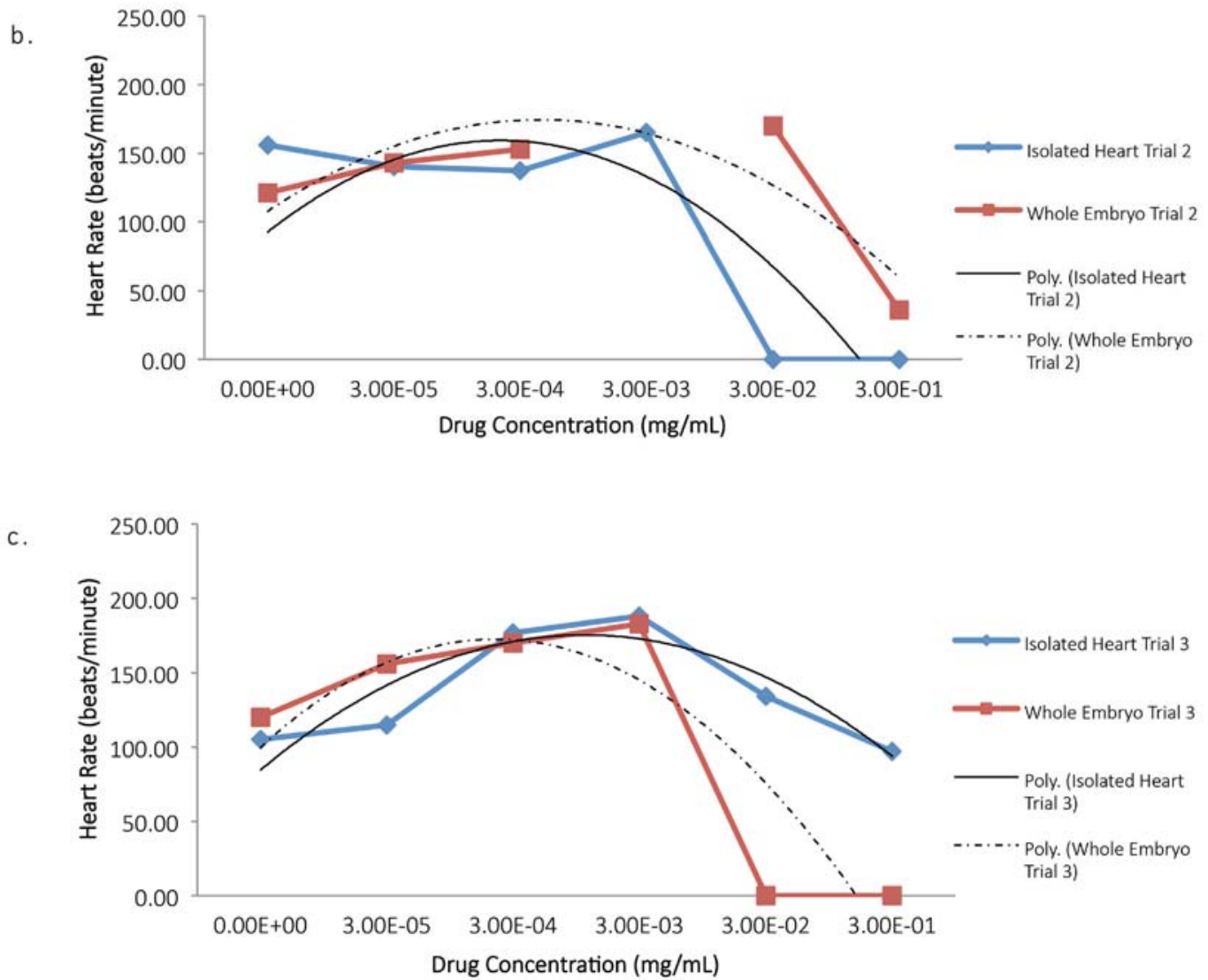

Figure 3. a, b, c. Polynomial Regression Curves illustrating HR of a 6-day isolated chick heart (blue) and whole embryo (red) exposed to varying concentrations of PSE. CMRL was used as the control (no drug). Figure 3 b., data for drug concentration $3.00 \mathrm{E}-03 \mathrm{mg} / \mathrm{mL}$ was not recorded. 


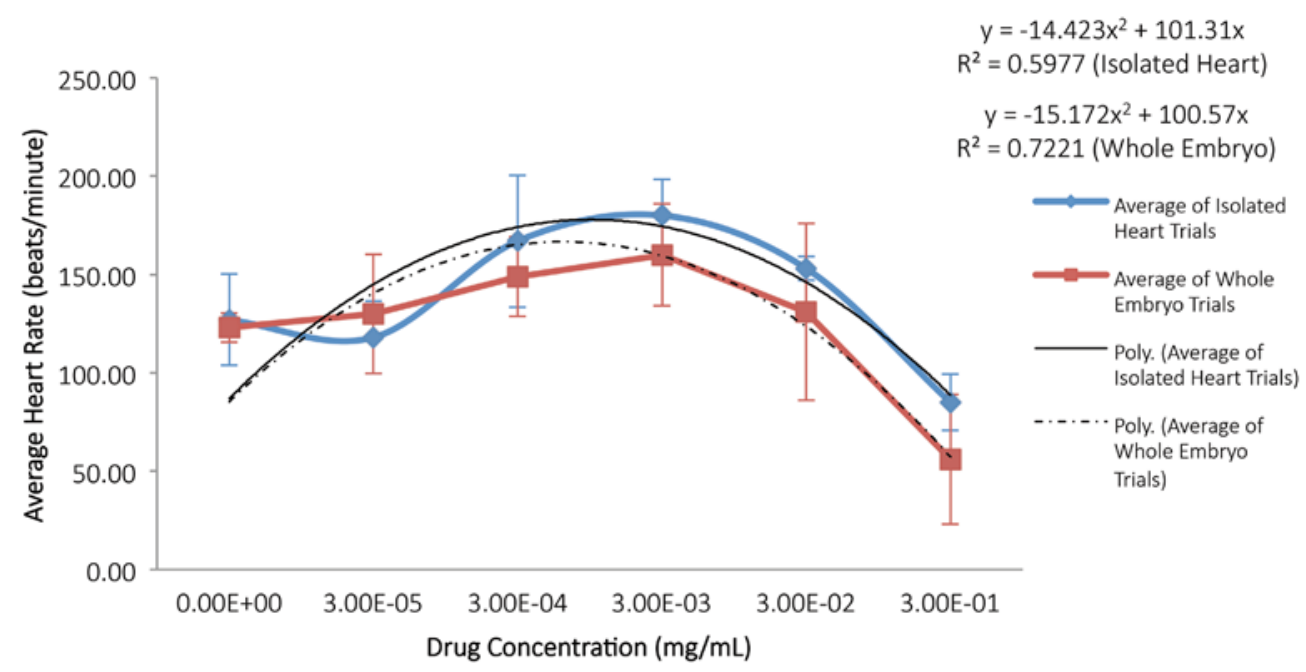

Figure 4. Polynomial regression representing average HR of 6-day isolated chick hearts (blue) and whole embryos (red) exposed to varying concentrations of PSE. CMRL was the control (no drug). Error bars represent the mean \pm 1 SD, for both the isolated hearts, in blue $(n=3)$ and the whole embryos, in red $(n=3)$.

\section{DISCUSSION}

The pharmacokinetics and pharmacodynamics of PSE are fairly well understood in various vertebrate model systems; however, no information exists on the effects of this drug on a vertebrate embryo. Not only did the experiment presented in this research paper intend to determine if PSE worked directly and/or indirectly on a fetal heart system, by utilizing five different PSE concentrations (lowest to highest), this research was also able to illustrate the dose-response relationship between this drug and its effects on the heart. It is important to note that around the lowest concentration, both isolated hearts and whole embryos showed normal sinus rhythm but increasing the doses of PSE caused abnormal changes in the electrical activity of the heart. The drug increased the HR to the point of tachycardia followed by atrial flutter and bradycardia at highest concentrations. In regards to this drug's mechanism of action, data suggests the following: both 6-day in vitro "isolated" chick hearts and whole chick embryos exposed to PSE showed the capability to respond to this drug. Based on the data, in both the isolated and whole embryo systems, the HR increased with increasing concentrations; however, at the highest concentrations, $3 \times 10^{-2} \mathrm{mg} / \mathrm{mL}$ and $3 \times 10^{-1}$ $\mathrm{mg} / \mathrm{mL}, \mathrm{HR}$ showed a copious fall along with various episodes of arrhythmias, especially atrial flutter. According to previous research conducted on anesthetized rats, PSE caused dose-dependent increases in HR, but after using the drug 6-hydroxydopamine (6-ODHA) for the destruction of sympathetic nerve terminals, these effects on the HR disappeared, suggesting that PSE's effect on HR was dependent on the presence of these nerves, i.e., an indirect effect. ${ }^{6}$ From these results in a fully developed vertebrate system, we reasoned that PSE would only increase the HR of the whole chick embryo with intact innervation (indirect effect), and not that of the isolated chick heart (direct effect). This was reasoned because previous research suggested that stimulation of PSE worked solely through the interaction between the sympathetic nervous system and the heart. However, the isolated heart no longer had external nerve supply which impaired the response to manipulations by the sympathetic system.

The data gathered did not support the hypothesis stated above, as the HR of the isolated chick hearts increased when exposed to this drug in increasing concentrations. Indeed, it appears that in the absence of innervation PSE, still worked directly, i.e., by binding to adrenergic receptors on the embryonic isolated chicken heart. As for the whole chick embryo, the experimental results could not differentiate an indirect effect from a direct effect, since there are both possibilities that PSE 
worked to increase HR by binding directly to adrenergic receptors or via stimulation of sympathetic nerve terminals. Therefore, for future research, whole embryos will be treated with 6-OHDA for the destruction of the sympathetic nerve terminals in the 6-day whole embryo to rule out indirect effects. Another factor that could have been involved in the results obtained in this study may be the developing heart system itself. PSE's effects on the developing 4-chambered heart may depend on the expression of adrenergic receptors and/or sympathetic nerve development.

PSE is an over-the-counter (OTC) medication commonly sold under the brand name Sudafed ${ }^{\varpi}$. It is used to temporarily relieve nasal congestion due to the common cold, hay fever or other upper respiratory allergies, and sinus congestion and pressure. It promotes nasal and/or sinus drainage, and works as a decongestant by shrinking blood vessels in the nasal passages. In terms of safety, this drug is of particular concern for pregnant women and young children. Recommendations by its manufacturer, Sudafed ${ }^{\circ}$, state that it should not be given to children under 4 years old or for longer than 7 days in a row. This drug is an FDA pregnancy category $\mathrm{C}$, which states animal reproduction studies have shown an adverse effect on the fetus and there are no adequate and well-controlled studies in humans. ${ }^{10}$ Adverse reaction data from human investigational studies and case studies suggest an evidentiary 4.2-fold increase risk of gastroschisis, a defect in the anterior abdominal wall through which the abdominal contents freely protrude in the first trimester with use of the decongestant. " Sympathomimetic drugs mimic the effects of neurotransmitter substances of the sympathetic nervous system, therefore drugs such as pseudoephedrine may activate $\alpha$-adrenergic receptors causing vasoconstriction in the uterine arteries, which may affect the blood flow to the fetus. This process could explain the association between the use of pseudoephedrine in the first trimester and the development of gastroschisis. Evidence proposes that this effect is negligible at recommended dosages; therefore, the drug may be given if the benefits justify the potential risk to the fetus. ${ }^{9}$ Based on experimental data gathered in this study on developing chick hearts and from the FDA Classification of Drug Safety During Pregnancy list, it appears that there is evidence of possible fetal risk. When pregnant women is taking Sudafed the baby also is exposed, for all substances cross the placenta through the umbilical cord and enter into the baby's bloodstream. Once in the embryo's bloodstream the drug may work directly and/or indirectly to increase HR in the fetus. When taken in high doses, it may lead to many arrhythmias and further complications to the embryo. The indistinguishable effect of the drug as seen in the study is significant because Sudafed ${ }^{\circ}$ is a commonly used decongestant. Without thorough understanding of the effects of the drug, it is difficult to ensure its safe use by the public. It is also important to reiterate that little research has been done on a vertebrate embryo. Therefore, further research is warranted to determine whether PSE will harm a developing human fetus in order to safeguard or prevent the use of the drug by pregnant women. This research shed some understanding as it assessed the effects of PSE on a developing heart system in various concentrations; studying dose response is central to determining "safe" and "hazardous" levels and dosages for drug. The data enclosed in this paper supports the finding of dangerous arrhythmias at elevated doses, while at low concentrations the isolated hearts and whole embryos illustrated a normal sinus rhythm. These observations suggest that the risks can be reduced if Sudafed is used as directed on the label, and not used in larger amounts.

Additionally, it is important to note that PSE is a key ingredient used to illegally produce the drug methamphetamine or "crystal meth" and is therefore kept behind the counters in local pharmacies in order to help keep drug abuse rates down. Pediatric pseudoephedrine use seems to be declining since the U.S. Congress passed the Combat Methamphetamine Epidemic Act of 2006. By law, products containing pseudoephedrine must now be sold behind the pharmacy counter and through online retailers who must meet certain requirement ${ }^{12}$. Given the adverse effects of PSE at high dosages presented in this paper and its ability to be converted into methamphetamine, it is strongly suggested that this drug be further regulated by becoming a prescribed medication. By making PSE less accessible, it may reduce the risks associated with the abuse of this drug and benefit society.

Overall, this research utilized denervated chick hearts, intact whole embryos along with various 
PSE concentrations to understand the pharmacodynamics of PSE on a developing vertebrate heart. Pharmacodynamics is the study of the biochemical and physiologic effects of drugs, dose-dependent relationships, and their mechanisms of action (drug/receptor interaction). Data illustrated that this drug increased the HR via a direct and/or indirect mechanisms on adrenergic receptors. These effects were dose-dependent and ranged by varying levels of exposure as more adverse effects were observed towards high concentrations. Understanding pharmacodynamics is critical for the clinical development of new drugs. Knowledge of such biochemical pathways is critical to finding the no-effect dose and the maximal effective dose so that an optimal therapeutic dose range can be selected. This research demonstrated that even though PSE can change the heart rate and cause arrhythmias, it does have a safe dose range, therefore risks can be reduced if taken in recommended amounts. However, the established dose range is based on studies in fully developed heart systems. Therefore, further research of this drug's effect on a developing vertebrate heart may help establish a more specific and safer dose range for pregnant women.

\section{ACKNOWLEDGMENTS}

We would like express gratitude to Dr. Jacqueline McLaughlin for her continuous commitment to undergraduate research and dedication to mentorship. We would also like to recognize Melissa Coyle for her aid in the laboratory and Justin Muser for sharing his knowledge in statistical analysis.

\section{REFERENCES}

[1] Hamburger, V. \& Hamilton, H. L. (1951). A series of normal stages in the development of the chick embryo. Journal of Morphology, 88: 49-92.

[2] Hamburger, V. \& Hamilton, H. L. (1992). A series of normal stages in the development of the chick embryo. 1951. Developmental Dynamics, 195(4): 231-72

[3] Hill, M.A. (2014) Embryology Chicken Development. Retrieved July 30, 2014, from //php.med.unsw. edu.au/embryology/index.php?title=Chicken_Development.

[4] Reece, J.B., Campbell, N.A., Urry, L.A., et al. (2009). Campbell Biology, 9th edition. Boston: Pearson.

[5]Bektas, F., Eken, C. \& Okta, C. (2010). Pseudoephedrine-induced paranormal supraventricular tachycardia: a case report. The Journal of Emergency Medicine, 38: 53-57.

[6] Kobayashi, S., Endou, M., Sakuraya, F., et al. (2003). The sympathomimetic actions of I-ephedrine and d-pseudoephedrine: Direct receptor activation or norepinephrine release? International Anesthesia Research Society, 97: 1239-1245.

[7] Cruz, Y.P. (1993). Laboratory Exercises in Developmental Biology. Academic Press, San Diego, California, 241 pages. [ISBN 0-12-198390-0][book]

[8] McLaughlin, J. S., \& McCain, E. R. (1998). Developmental and physiological aspects of the chicken embryonic heart. Tested Studies for Laboratory Teaching, Volume 20. (C.A. Goldman, editor). Proceedings of the 20th Workshop/Conference of the Association for Biology Laboratory Education $(A B L E), 20: 85-100$.

[9] Wallace, Rosa. "Graphing Resources." Using Descriptive Statistics. National Science Foundation, 16 May 2005. Web. 6 Feb. 2015.

[10] Black, R.A. \& Hill, D.A. (2003). Over the counter medications in pregnancy. American Family Physician, 67: 2517-2524.

[11] Werler, M.M., Sheehan, J. E. \& Mitchell, A.A. (2002). Maternal medication use and risks of gastroschisis and small intestinal atresia. American Journal of Epidemiology, 155: 26-31.

[12] Vernacchio, L., Kelly, J.P., Kaufman, D.W., et al. (2008). Pseudoephedrine use among U.S. children, 1999-2006: results from the Slone Survey. Journal of the American Academy of Pediatrics, 122: 1299-1304. 


\section{ABOUT THE STUDENT AUTHORS}

Samely Gonzalez is a current undergraduate student at Penn State Abington, Philadelphia, PA set to graduate in May, 2016 with a B.S. degree in Genetics and Developmental Biology. She plans to utilize her skills and knowledge from undergraduate research and other science experiences in her pursuit to become a physician assistant. Her overall objective is to have a career in the medical field that allows her to help others achieve a healthy way of living.

Fatima Afzal is from Bethlehem, Pennsylvania and is currently enrolled as an undergraduate sophomore at Penn State Berks, Reading, PA. She has declared her major in biochemistry, pursing the cell and molecular biology option. She plans on applying the acquired research skills to future careers in pharmaceutical companies or as a medicinal chemist, working alongside eager scientists to develop and manufacture pharmaceuticals in order to grow and expand the drug industry.

\section{PRESS SUMMARY}

Pseudophedrine (PSE) is an over the counter (OTC) medication commonly used to temporarily relieve nasal congestion, upper respiratory allergies, and sinus pressure. Previous research has shown, however, that this drug elevates heart rate and blood pressure in humans and other mammals. This research utilized the chick embryonic heart as a model system to study the effects of (PSE) on the developing, vertebrate four-chambered heart and to determine whether this drug has either direct or indirect effects, i.e., it works by binding directly to receptors in the heart's pacemaker or indirectly by causing the release of norepinephrine from sympathetic nerve terminals to activate the same receptors. To do this, isolated developing chick hearts without innervation and whole chick embryos were exposed to varying PSE concentrations and heart rates were recorded. Research suggests that this drug has both direct and indirect effects and induces atrial flutter when exposed to high dosages. 